\title{
Presentación de la revista Deusto Estudios Cooperativos
}

La revista Deusto Estudios Cooperativos es una publicación que puede considerarse como la sucesora del Anuario de Estudios Cooperativos, una revista esta última que desde su nacimiento, en 1985, resultó ser pionera en el ámbito de la Economía Social y el Cooperativismo, manteniendo su actividad, de forma ininterrumpida hasta el año 2001.

La nueva revista Deusto Estudios Cooperativos, editada por el Instituto de Estudios Cooperativos de la Facultad de Derecho de la Universidad de Deusto, se crea con la intención de mantener la esencia del Anuario de Estudios Cooperativos, deseando cumplir el objetivo de la divulgación de trabajos originales en materia de Cooperativismo y Economía Social.

La revista comenzó a publicarse en un año ciertamente significativo, el año 2012. Un año relevante por dos motivos. En primer lugar, porque ese año fue proclamado como el Año Internacional de las Cooperativas por parte de la Asamblea General de las Naciones Unidas, poniendo, de este modo, en evidencia la relevancia de las cooperativas en el desarrollo económico y social, en la reducción de la pobreza, la creación de empleo y la integración social. Y, en segundo lugar, porque en 2012 la Universidad de Deusto celebró su 125 Aniversario, con lo que la publicación de la revista Deusto Estudios Cooperativos constituyó un reflejo del compromiso mantenido por la Universidad con la investigación en materia de Economía Social.

Con esta publicación se pretende contribuir a dar a conocer que el modelo cooperativo es una fórmula eficaz de emprender actividades empresariales. Precisamente, las cooperativas representan un modelo de empresa democrática, responsable y ética, una empresa que pone el foco de su atención en las personas y en el medio ambiente, promoviendo el crecimiento económico y la justicia social. Esto es, se trata de un modelo de empresa que se fundamenta en el diálogo y en los idea- 
les de paz, impulsando el respeto por los derechos y las libertades humanas y la solidaridad.

El presente monográfico constituye el segundo número dedicado al estudio del movimiento cooperativo en Cuba. Con él se pretende completar el estudio de la problemática y de los retos de las cooperativas en Cuba, con las contribuciones del profesor Fernández Peiso, de Héctor Mata, de Orestes Rodríguez Musa, de Orisel Hernández Aguilar, de Deibby Valle Rios y José Manuel Figueroa González; y de Yaumara Acosta Morales. A todos ellos, nuestro sincero agradecimiento por elegir nuestra revista para publicar sus valiosos trabajos de investigación.

Un afectuoso saludo cooperativo,

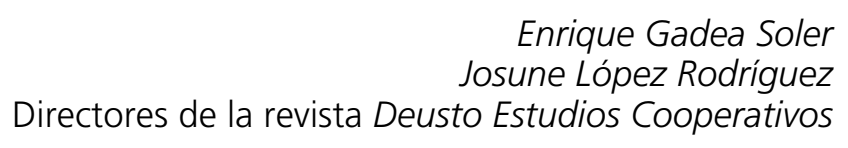




\section{Derechos de autor}

La revista Deusto Estudios Cooperativos es una revista de acceso abierto lo que significa que es de libre acceso en su integridad inmediatamente después de la publicación de cada número. Se permite su lectura, la búsqueda, descarga, distribución y reutilización legal en cualquier tipo de soporte sólo para fines no comerciales y según lo previsto por la ley; sin la previa autorización de la Editorial (Universidad de Deusto) o el autor, siempre que la obra original sea debidamente citada (número, año, páginas y DOI si procede) y cualquier cambio en el original esté claramente indicado.

\section{Copyright}

The Deusto Journal of Cooperative Studies is an Open Access journal which means that it is free for full and immediate access, reading, search, download, distribution, and lawful reuse in any medium only for non-commercial purposes, without prior permission from the Publisher or the author; provided the original work is properly cited and any changes to the original are clearly indicated. 